\title{
CFD analysis of wind blocking vs. venturi effect: a case study in tropical climate
}

\begin{abstract}
Wind catchers are structures used for natural ventilation using the two basic principles of stack effect and wind induced natural ventilation and has recently attracted a lot of attention due to relying only on the free sustainable energy of wind and hence being able to reduce energy expenditure and greenhouse gas emission to a considerable amount. Even though this structures have been used for thousands of years in Iran and other regions of the Middle East but due to the low temperature difference between the indoor and outdoor in hot and humid climates these structures have not been used. However by the finding that stack ventilation has negligible effect on the ventilation compared to wind induced ventilation, hopes have arisen to provide comfort and high ventilation rates by high air exchange rates. Venturi shaped roof as one of the most effective way of producing driving force for ventilation is studied in this paper. A specific venturi shaped roof in University of Putra Malaysia was considered and a case study and CFD simulations were performed. The results showed that the venturi effect could be seen in the specific roof and hence a correct choice of ventilation technique and design has been applied for this case. Even though the results are optimistically stated and further studies and validation is required but could be a good initiation towards more efficient use of sustainable energy sources.
\end{abstract}

Keyword: Computational fluid dynamics; Natural ventilation; Venturi-effect; Wind-blocking effect; Buildings; Energy efficiency; Tropical climate 